\title{
Contract Risk Analysis for Turnkey Project Bid: a Case Study
}

\author{
by C.B. Chapman and Dale F. Cooper*,**
}

\begin{abstract}
This paper describes a risk analysis undertaken for a consortium of engineering consulting firms who were favoured bidders for a turn-key thermal electric power project in the Middle East. The risk analysis pursued two areas: the development of a cash-flow model for the project; and the development of an understanding of project risk in qualitative terms with respect to individual sources of risk and their combined effect. Integration of these two areas produced results which demonstrated a relatively large spread in the total project cost. Means of reducing this spread through contractual countermeasures, contingency plans and balancing uncorrelated risks are presented, along with an assessment of their implications.
\end{abstract}

\section{Introduction}

This paper describes a risk analysis undertaken for a consortium of engineering consulting firms who were favoured bidders for a turn-key thermal electric power project in the Middle east. A fixed price tender was required. The consortium did not have the capitalization to undertake any significant financial risks, but the prospective client and the home government were making supportive offers. These included substantial advance payments to be invested in trust for the consortium to provide a hedge against inflation, and home government insurance on inflation of domestic content above specified ceiling rates. The study addressed the question"should the consortium bid, and if so, at what level?"

The risk analysis pursued two areas. One was the development of a computer-based cashflow model for the project. The other was the development of an understanding of project risk in qualitative terms with respect to individual sources of risk and their combined effects.

* Department of Accounting and Management Science, University of Southampton and Acres International Management Services. ${ }^{* *}$ Spicer and Pegler Associates, London. Paper prepared for the Third Management of Risk in Engineering Seminar, sponsored by the Geneva Association, Glasgow, 17-19 April 1985. 
The computer-based cash-flow model was constructed to enable translation of bid assumptions or alternative contract specifications into a cash-flow and profit picture, and to ensure a clear understanding ot the implications of various issues. It also facilitated sensitivity analysis to identify critical assumptions, and helped develop a set of scenarios representing the range of situations which might occur.

The qualitative analysis was pursued in order to develop a comprehensive list of potential sources of risk and an understanding of the scale and relative importance of the potential sources. The qualitative analysis also allowed assessment of various tactics to achieve control or reduction of risks from specific sources, and assessment of various strategies for overall project risk reduction.

The two areas of development were integrated and developed interactively. The results demonstrated a relatively large spread in the total project cost. Means of reducing this spread through contractual counter measures, contingency plans and balancing uncorrelated risks were presented, along with an assessment of their implications.

\section{General approach}

\section{Study emphasis}

There are many approaches to risk analysis, and they can be classified in a variety of ways. Of special importance is the degree to which four aspects of any comprehensive risk analysis receive emphasis:

1. measurement of risk;

2. risk reduction via contractual countermeasures like insurance, stop cost clauses, and fixedprice cost components;

3. risk reduction via planned operating counter-measures;

4. risk reduction via a balanced portfolio of risks.

In general, quantitative risk analysis becomes more difficult as the emphasis shifts from 1 to 4 , but cost-effectiveness increases.

Measurement of risk is usually a necessary component of risk analysis, and risk reduction via activity-oriented countermeasures like contingency plans becomes vital once a contract is obtained. However, given a reasonable feel for the risks involved, the vital aspects of risk analysis for bidding purposes are risk reduction via contractual countermeasures and risk reduction via a balanced portfolio of risks, taking into account the lack of correlation between uncertain variables to the extent possible. The approach adopted here represents the authors' view of an effective way to reflect these priorities with respect to a contract bid in the circumstances described earlier, with features which are relevant to a wide range of circumstances.

\section{Cash-flow model}

A computer-based cash-flow model was constructed for five reasons.

First, to ensure a clear understanding of the implications of insurance against escalation and similar issues. 
Second, to perform the arithmetic required to translate the base case bid assumptions into a cash-flow and profit picture.

Third, to facilitate sensitivity analysis with respect to the assumptions of the base case bid, allowing a large set of individual assumption variations to be evaluated for comparison with the base case. This analysis helped to identify sensitive or critical assumptions, and translated uncertainty with respect to those assumptions into uncertainty with respect to project profitability.

Fourth, to facilitate the development of a set of scenarios which represented, in a simplified form, the range of situations which might develop. These scenarios helped to identify the implications of correlation between sources of risk, and to translate uncertainty with respect to the project as a whole into profitability terms.

Fifth, to assist in the development of charts, graphs and similar aids, to be used during contract negotiations to facilitate rapid assessment of the implications of alternative contract specifications.

\section{Qualitative analysis}

The development of an understanding of project risk in qualitative terms was pursued with four sets of goals in mind.

First, to develop a comprehensive list of potential sources of risk.

Second, to develop an understanding of the scale and relative importance of these potential sources of risk.

Third, to assess the extent to which these potential sources of risk were neutralized by the proposed conditions of the bid contract in terms of remedies for specific sources of risk; to assess the residual risk; and to assess the extent to which alternative conditions of the contract oriented towards specific risk sources might affect residual risks. In summary, this goal was assessment of tactics for the reduction and control of specific risk sources.

Fourth, to assess the extent to which project risk as a whole was neutralized by the bid contract, bearing in mind the extent to which individual risks were likely to be realized simultaneously, and contractual coverage for risks of a general nature; to assess the residual risk associated with the project as a whole; and to assess the extent to which alternative forms of contract might affect the residual risk associated with the project as a whole. In summary, this goal was assessment of strategies for risk reduction and control.

\section{Integration}

The cash-flow model and the qualitative analysis were integrated and developed interactively to produce the analysis which follows. Overlap occurred especially in three areas. The understanding of the implications of escalation insurance and similar issues developed when constructing the cash-flow model formed an input to the development of a comprehensive list of risk sources. The sensitivity analysis performed with the cash-flow model linked with tactical risk reduction and control analysis to provide an assessment of the residual risk associated with individual sources of risk in terms of project profit. The development of scenarios 
Table 1: Sources of risk and offsetting tactics

\begin{tabular}{|c|c|c|c|c|c|c|c|c|c|c|c|c|c|c|}
\hline \multirow[b]{2}{*}{ Risk source } & \multicolumn{14}{|c|}{ Tactic to offset } \\
\hline & 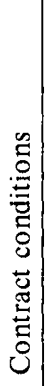 & 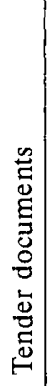 & 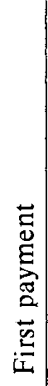 & 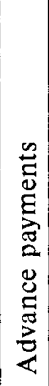 & 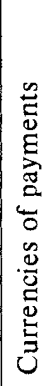 & 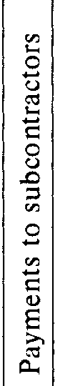 & 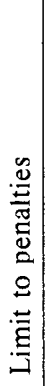 & 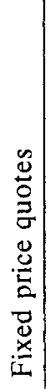 & 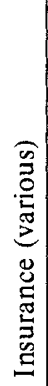 & 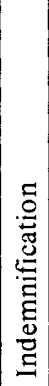 & 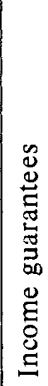 & 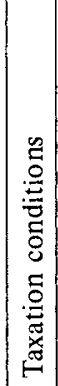 & 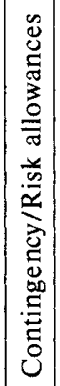 & 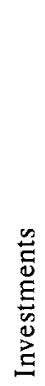 \\
\hline 1. Client cancels & $\bullet$ & & & $\bullet$ & & & & & $\bullet$ & & & & & \\
\hline 2. Client fails to pay & $\bullet$ & & & $\bullet$ & & & & & $\bullet$ & & & & & \\
\hline 3. Client suspends & $\bullet$ & & & & & & & & & & & & & \\
\hline 4. 'Force Majeure' incident & - & & & & & & & & $\bullet$ & & & & & \\
\hline 5. Contractor cancels & $\bullet$ & & & $\bullet$ & & & & & & & & & & \\
\hline 6. Contractor suspends & $\bullet$ & & & & & & & & & & & & & \\
\hline 7. Client acceptance delay & & $\bullet$ & $\bullet$ & & & & & & & & & & & \\
\hline 8. Client start delay & $\bullet$ & & & $\bullet$ & & & & & & & & & & \\
\hline 9. Suppliers start delay & $\bullet$ & & & & & & $\bullet$ & & $\bullet$ & $\bullet$ & & & & \\
\hline 10. Transport start delay & $\bullet$ & & & & & & & & $\bullet$ & & & & & \\
\hline 11. Contractor start delay & 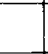 & & & & & & $\bullet$ & & $\bullet$ & & & & & \\
\hline 12. External start delay & $\bullet$ & $\bullet$ & $\bullet$ & & & & & & $\bullet$ & & & & & \\
\hline 13. Client duration extension & $\bullet$ & & & $\bullet$ & & & & & $\bullet$ & & & & & \\
\hline 14. Suppliers duration extension & $\bullet$ & & & & & & $\bullet$ & & $\bullet$ & $\bullet$ & & & & \\
\hline 15. Transport duration extension & $\bullet$ & & & & & & & & $\bullet$ & & & & & \\
\hline 16. Contractor duration extension & & & & & & & $\bullet$ & & $\bullet$ & & & & & \\
\hline 17. External duration extension & $\bullet$ & & & & & & & & $\bullet$ & & & & & \\
\hline 18. Base cost estimation error & & & & & & & & $\bullet$ & & & & & $\bullet$ & \\
\hline 19. Escalation estimation error & & & & & & & & & $\bullet$ & & & & & \\
\hline 20. Exchange rate excalation error & $\bullet$ & & & & $\bullet$ & $\bullet$ & & & & & & & & $\bullet$ \\
\hline 21. Investment income estimation error & & & & & & & & & & & $\bullet$ & $\bullet$ & & \\
\hline 22. Investment error & & & & & & & & & & & & $\bullet$ & & \\
\hline 23. Supplier performance failure & & & & & & & $\bullet$ & & $\bullet$ & $\bullet$ & & & & \\
\hline 24. Contractor performance failure & & & & & & & & & $\bullet$ & & & & & \\
\hline
\end{tabular}


employing the cash-flow model linked with strategic risk reduction and control analysis to provide an assessment of the residual risk associated with the project as a whole in terms of profit.

\section{Tactics to reduce risk from specific sources}

A number of specific sources of risk were identified, some of which were fairly broad. They are enumerated in Table 1, and linked to tactics to off set their impact. A qualitative assessment of the effectiveness of these tactics followed, along with a discussion of some alternatives. An example is shown in Table 2.

Table 2: Qualitative assessment of tactics to offset the risk of cancellation by the client

RISK SOURCE: Cancellation by client

\section{TACTIC TO OFFSET:}

(a) Advance payments exceeding costs to date

(b) Contract clause: $5 \%$ cancellation fee plus costs once under way, section 1.01

(c) Contract repudiation insurance

\section{DISCUSSION}

The draft contract section 1.01 would seem to eliminate this source of risk if the project proceeds as planned. However, a combination of cost overruns, delays, high cost inflation and/or return on fee advances could lead to a difficult position in the later years of the project, especially if fee advances are not as substantial as anticipated. To partially cover this, section 1.01(d) could be extended to define borrowing costs as costs for these purposes, although the reciprocal deduction of income earned on fee advances would probably have to be included if this were done.

Contract repudiation insurance presumably applies to the residual risk after the application of section 1.01. It would seem to have limited value unless it specifically covers failure to pay under 1.01(d) and failure to pay when borrowing is forced upon the contractor in the extended 1.01(d) context.

It is assumed section 1.01(a) does not limit the client's right to cancel. This being the case it would be worth emphasizing the absence of any limitations to strengthen the argument for a riskless position should the client decide to cancel. There would seem to be little value in attempting to institute restrictions. The client could easily get around any restriction indirectly in any case, causing more problems than would arise if a direct approach were used. 


\section{Base case bid cash-flow analysis}

A base case bid cash-flow analysis was performed using a computer cash-flow model. It employed 'base cost' figures, represented in percentage form in Table 3. The figures used were expected costs. They assumed no substantial political or work delays, and were conditional upon this assumption. They did include some expected effects of other sources of delay.

Table 3: Base case costs as percentage of the total cost

COST ITEM $\%$

1. Project Management 9

2. Turbine and Electrical $\quad 24$

3. Boilers 13

4. Miscellaneous Equipment (Home) 7

5. Miscellaneous Equipment (Foreign) 5

6. Erection (Home) 1

7. Erection (Foreign) 13

8. Civil Works (Foreign) 15

9. Spares and Training 1

10. Insurance, Guarantees, Agents Commissions 4

11. Contingency 4

12. Risk Allowance 4

\section{Base cost estimation}

Items 1 through 9 in Table 3 were estimated in three stages.

First, initial estimates were derived from a breakdown of component activities and expenditures. These figures were free of contingency allowances, with the exception of a few highly likely minor items. They assumed a 54-month base schedule from the start of work to the commissioning of all generating units, and were conditional upon this assumption.

Second, the initial estimates were related to conditional cost probability distributions defined in terms of optimistic, pessimistic, and most likely values, with associated derived expected values (Figure 1). 


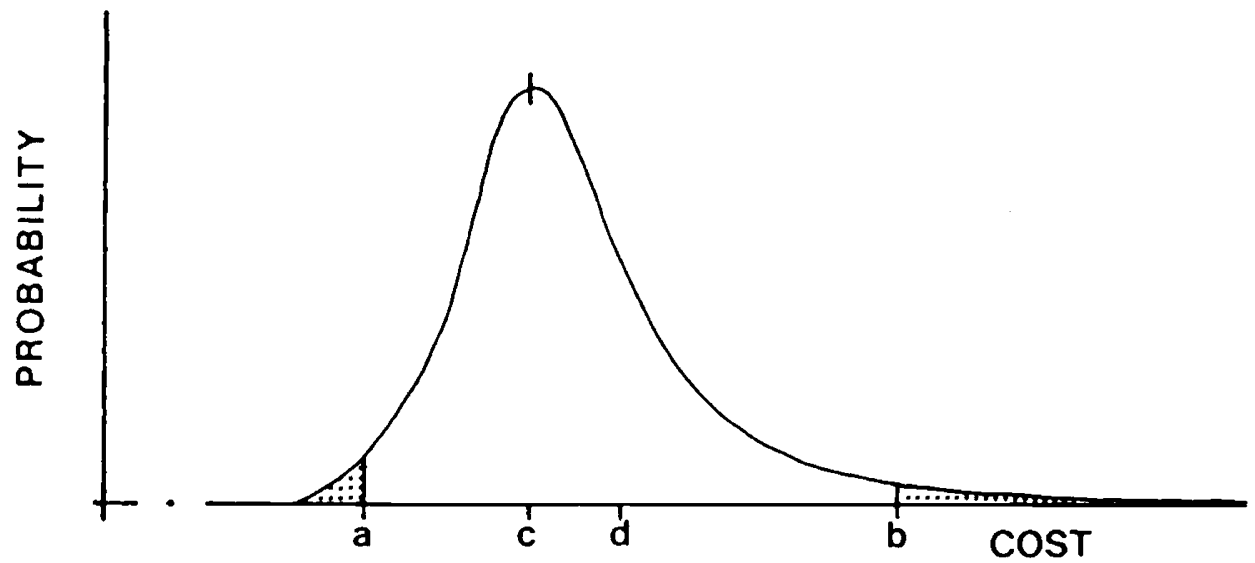

Figure l: Definition of a cost distribution in terms of (a) optimistic, (b) pessimistic, and (c) most likely values. The tail areas each contain $5 \%$ of the distribution. The expected value $(d)$ is derived from the other parameters.

Third, the second stage values were adjusted, when necessary, for an expected delay of six months, to yield expected values which were no longer conditional on the base schedule. The six month expected delay was associated with a probability distribution for project duration reflecting delays induced by suppliers, transport, erection and commissioning. Its shape was similar to the cost probability distribution in Figure 1. The corresponding values were:

(a) Optimistic no delay (54 months to completion)

(b) Most likely 3 months delay

(c) Expected 6 months delay

(d) Pessimistic 18 months delay

An expected delay of 6 months was associated with a general spreading of the schedule from month 24 onwards.

For each item, when relevant, the increase in expected cost associated with a 6-month delay to the project was estimated assuming a delay originating elsewhere. When relevant, the increase in expected cost associated with a 6-month delay originating with the item itself was also estimated, and these two figures were averaged, using weights proportional to the probabilities of the two kinds of delays occurring. Adding the expected cost increases as a consequence of delay to the original conditional estimates yielded the 'base cost' figures represented in Table 3.

As a consequence of this approach, the base cost estimates considered the expected or average implications of delays, with the exception of substantial political or work delays. It was assumed that these exceptions would be covered by contract clauses. 
Within the framework of this approach, the information used to produce the figures in Table 3 was considered item by item for items 1 to 9 , using a combination of quantitative assessment supported by verbal discussion (Table 4). A slightly different approach was adopted for items 10,11 , and 12 .

Table 4: Assessment of cost distribution for project management and turbine and electrical equipment

\section{PROJECT MANAGEMENT}

The initial estimate here was 17.1, derived from a breakdown of the component engineering, administration and site supervision activities. This initial estimate was associated with a cost probability distribution defined in terms of the following values:
(a) Optimistic
15.2
(b) Most likely
17.1
(c) Expected
18.3
(d) Pessimistic
21.3

Project delay was assumed to involve additional costs at a rate of 8 per cent per annum. An expected delay of 6 months consequently results in an additional cost of 0.7 , yielding a base cost estimate of 19.0 .

\section{TURBINE AND ELECTRICAL}

The initial estimate was 23.7. This estimate embodies suppliers contingencies, but it does not reflect potential variations between now and the signing of a fixed price 19XX contract. It was related to a conditional cost probability distribution as discussed above, with corresponding values as follows:
(a) Optimistic
23.4
(b) Most likely
23.7
(c) Expected
24.0
(d) Pessimistic
24.6

It was agreed we could assume delivery on time, and payment on time, with no delay-related base cost changes. Suppliers are expected to be responsible for about 10 per cent of the delays discussed above. This means our assumptions are mildly pessimistic, in so far as when delay is induced by delayed supply of turbines and electrical equipment, some of the later payments will also be delayed with consequential cost savings. But this bias is probably more than balanced by storage costs which will be incurred when suppliers are not responsible for delay. Storage costs were not considered in our calculations.

Insurance, Guarantees, Agents Commissions (Item 10): It was assumed this item would be firm by the time a bid was submitted, so the initial estimate was used directly. 
Contingency (Item 11): The use of expected values for items 1 to 9 involved the addition of a contingency to the initial figures. This specific contingency amount was what should be expected, in the sense that on average it would be required, and it was calculated with respect to the individual items which give rise to it. For these reasons it was appropriate to include these amounts in the base case bid figures. In addition to this contingency, a contingency was required to cover two further factors: errors or omissions with respect to the estimation of expected costs for individual items as described above; and the impact of factors whose effects were explicitly avoided when calculating the expected costs. As the contingency required here could not be related to specific items, it had to be treated as a separate item. Its size was determined in terms of a reasoned judgement of the probable impact of the two factors above.

Risk Allowance (Items 12): Insurance cover for some sources of risk was provided in part by the payment of premiums which make up the bulk of item 10 . This item did not include a risk allowance for the self-insured aspects of these risks. A contractor ought to charge a fee for such coverage, as the Government or an insurance company would. It should reflect the probability of a loss, the expected loss if a loss occurs, any administrative costs, and an allocation for taking the risk which should reflect the contractor's ability to take risks. In addition, a contractor ought to charge a risk allowance for managing the project. The size of this allowance was determined in terms of a reasoned judgement based upon the risk analysis.

\section{Cash-flow distribution}

Cash-flow for these 12 items was distributed between the scheduled start and scheduled completion dates by quarters, using approximations to the patterns of payments observed in similar projects, with a 6-month expected delay spread over the last 3 years of the schedule.

\section{Escalation}

Insurance, guarantees and agents commissions (Item 10) was the one item not subjected to escalation. All other domestic content items were escalated. Foreign content items were escalated using a different rate.

\section{Interest Income}

Interest income was assumed to be earned on positive quarterly balances. The program assumed the same rate for interest charges on negative balances, but these did not occur for the base case, and different rates could have been used if appropriate.

\section{Profit}

The base case produced zero profit, to the nearest million dollars, apart from the normal profits in the subcontract packages. Profits could have been associated with the contingency allowance and risk premium, but it was more appropriate to assume these extra costs would occur for analysis purposes. 


\section{Sensitivity analysis}

Sensitivity analysis changed one assumption associated with the base case at a time, to evaluate the impact of each assumption on the profit or loss of the project. Factors examined included: base cost estimating errors; escalation estimation error; political delay; supplier delay; and construction delay.

The sensitivity analysis suggested significant risk exposure with respect to base cost estimating error (Figure 2). With respect to estimated income from fee advances, assuming the proposed base case payment schedule, the key risk was failing to obtain guarantees while having to accept lower return rates. Delay on its own was a less important source of risk once the contract was signed, given a flexible 'Force Majeure' clause, but delay in signing was a risk which was assumed to be realized. (The term 'Force Majeure' was defined as 'Act of God, strikes, lockouts, or other industrial disturbances, acts of the public enemy, wars whether declared or not, blockades, insurrections, riots, epidemics, landslides, hurricanes, earthquakes, storms, lightning, floods, washouts, civil disturbances, explosions and other causes similar to the kind herein enumerated or equivalent force not within the control of either party and which by the exercise of due diligence neither party is able to overcome.') The terms of payment was a critical area identified as requiring further analysis, especially in its interaction with the revenue question. Escalation on its own was not a major source of risk, given the assumptions with respect to escalation insurance.

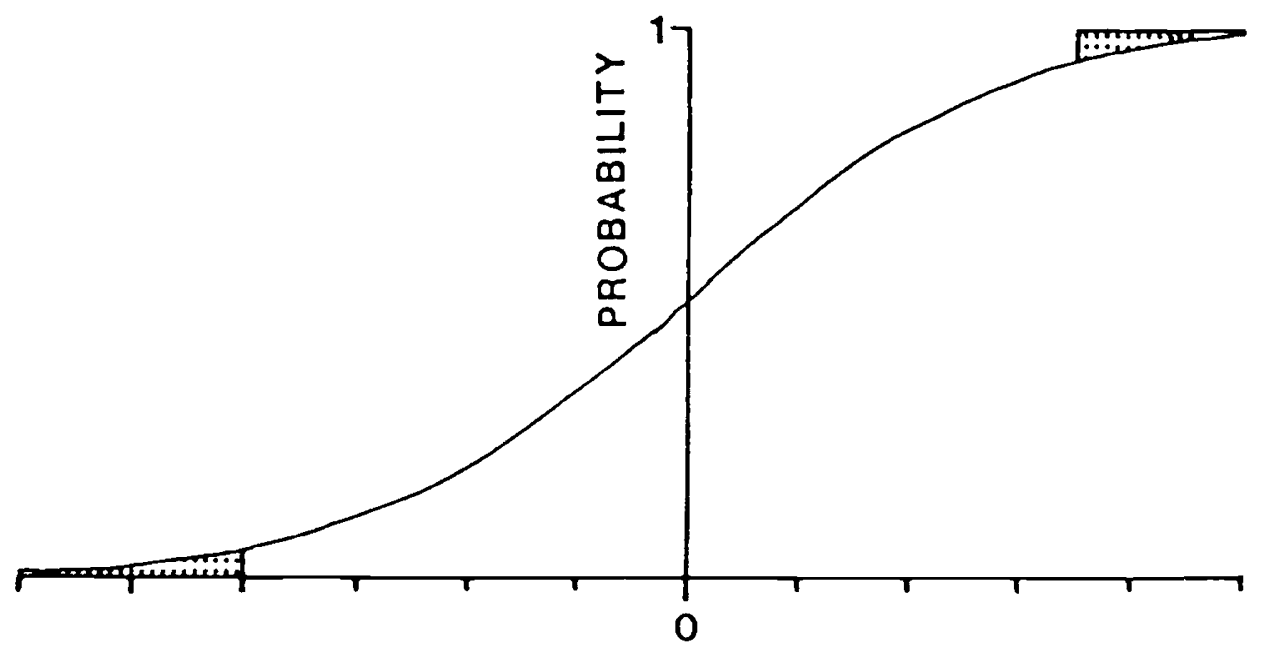

LOSS

PROFIT

Figure 2: Distribution of profit or loss with respect to estimating errors in the base costs. 


\section{Strategies to reduce overall risk}

\section{Major sources of risk and their correlation}

There were four major sources of significant residual risk, assuming a contract modified as suggested by the tactical analysis, the base case payment scheme, and no currency risk problems:

1. base cost estimating error;

2. delays, with or without the application of "Force Majeure";

3. high rates of cost escalation;

4. low rates of return on fee advances.

It was assumed that to some extent 1 and 2 were positively correlated. On the one hand, delaying the start of construction by a year, for example, would boost the base cost, quite apart from escalation associated with the delayed cost pattern, because of the holding operation forced upon the contractor. On the other hand, an underestimated base cost should not in itself cause delays. Positive correlation was not complete or perfect, but it existed in part. To some extent, the realization of both sources of risk simultaneously had to be anticipated. In particular, 1 had to be anticipated if 2 occurred, although 2 was not necessary if 1 occurred.

To some extent, both 1 and 2 were assumed to be positively correlated with 3 as well, and related to the state of the economy. Again, this correlation was not perfect, but it existed in part, and to some extent the realization of all three sources of risk simultaneously had to be anticipated. In particular, 1 and 2 were anticipated if 3 occurred, although 3 was not necessary if 1 and/or 2 occurred.

\section{Scenario analysis}

To quantify the implications developed above, and to gain a feel for residual risk, as strategies to reduce it were developed, a number of scenarios were constructed in addition to those associated with the sensitivity analysis. These examined risks associated with: domestic cost escalation; foreign cost escalation; project delay for an additional 12 months; a pessimistic payment schedule; and the terms of subcontracts for foreign civil works and foreign erection. It was difficult to summarize overall risk, especially in the absence of confirmation of critical assumptions related to escalation insurance and fixed price and escalation rate contracts for erection and civil works. However, an 'expected' view of the possibilities suggested a wide range of potential profit and loss, with large losses or large windfall profits both likely.

\section{Fee advances}

Investment of fee advances had three purposes:

1. to generate income as an alternative to direct fee payments;

2. to provide partial protection against high rates of cost escalation, on the assumption that rates of return would tend to rise if cost inflation increased;

3. to provide partial protection against delays, on the assumption that the extra income generation time would provide extra income to meet cost increases. 
The effectiveness of the fee advance scheme with respect to all three purposes clearly increased dramatically with the rate of return earned and the extent of the fee advances. It also increased dramatically with the degree of negative correlation between the rate of return and the extent to which risk sources 1,2 , and 3 were realized.

\section{Portfolio of equities and bonds}

In the absence of any overall risk reduction strategies, the joint risk exposure associated with base cost estimates, delays and escalation were enormous. Potential losses due to these sources of risk were an order of magnitude greater than any conceivable investment risk. However, it was not difficult to show numerically that a highly geared portfolio of equities plus a reasonable selection of bonds, with some of the bonds (but not all of them) maturing as cash was required, could substantially reduce total risk. In effect, the investment side was only likely to come unstuck when the other sources of risk were realized to minimal extent, and there was likely to be a significant increase in revenue when all the other sources of risk were realized to a substantial extent.

\section{Stop cost clause}

The portfolio approach discussed above was accepted as an important first line of defence by all members of the consortium. However, some members wanted to press for a stop cost clause, making the client responsible for cost overruns beyond a specified loss limit, to guarantee no loss for the consortium. Other members of the consortium were convinced the client would not accept such a clause. Analysis of the implications of a stop cost clause from the client's perspective was used to demonstrate that such a clause did not provide a guarantee. It reduced the risk, but a significant residual was transformed into 'client refusing to pay'. As a consequence, it was not worth pressing for.

\section{Limited liability}

A limited liability position for the consortium and its associates was considered. However, as the home government was involved as an associate, this was not deemed an acceptable position, even if the client accepted it, and it would clearly be unwise of the client to do so.

\section{Explicit insurance for cost overrun}

Several possibilities were explored, including home government insurance on a profit sharing basis. Agreement on a suitable vehicle was not obtained. No bid was made.

\section{Conclusion}

The price quoted for a fixed price turnkey project must be based upon rather complex and interdependent assumptions. Most of these assumptions involve a considerable degree of uncertainty, and this uncertainty generates risk. The bid described here received considerable attention with respect to risk reduction, but significant residual risks remained. 
The expected rewards were high, but the consortium decided not to bid. History suggests some wisdom in this decision, and the risk analysis was given credit for contributing to the process of acquiring it. It might be argued that if adequate risk analysis leads to non-bidding, doing such risk analysis is analogous to purchasing paralysis. It might also be argued that a bid was not made for reasons not discussed here, and that a successful bid could have been made and a large profit secured if more effort had been expended considering explicit insurance for cost overrun. However, a successful bid not based upon such analysis would probably have lead to considerable financial discomfort for the consortium and the home government.

In the authors' view the risk analysis process was well worth while. The senior officers of the consortium companies, who were directly involved in its interpretation, seemed to share this view. One of the authors' current concerns is attempting to ensure risk analysis facilitates the arrangement of appropriate insurances in such circumstances.

This case study demonstrates that risk analysis need not require detailed quantification. Representative scenarios were employed, but the likelihood of their occurrence was not assessed in precise numerical form. The concern was avoiding or neutralising all significant sources of risk via contractual arrangements with the client, the home government, sub-contractors and insurance companies. Probabilities may be largely irrelevant in this context.

The risk analysis model used here took a verbal form, in terms of structured lists of risks and responses, with backup discussion and documentation. Much of the initial input came from legal, insurance and economic advisors, but the formal lists and assessments were the product of extensive discussion at meetings involving the senior officers of the consortium companies. Structured verbal models of this kind can be extremely useful, especially when the nature of risks and associated responses may cause confusion or misunderstanding if an agreed definition is not provided, and when inputs from specialists with expertise in diverse fields must be integrated coherently. Such verbal models also provide the framework and the assumptions for subsequent quantification, and a useful store of corporate knowledge. This conclusion has been sustained in numerous case studies $1,2,3,4$.

\section{REFERENCES}

1. CHAPMAN, C.B. and COOPER, D.F. (1983): "Risk analysis: testing some prejudices", European J. Operational Research, 14 (3): 238-247.

2. CHAPMAN, C.B., COOPER, D.F. and CAMMAERT, A.B. (1984): "Model and situation specific OR methods: risk engineering reliability analysis of an LNG facility", J. Operational Research Society, 35 (1): 27-35.

3. CHAPMAN, C.B., PHILLIPS E.D., COOPER D.F. and LIGHTFOOT L. (1985): "Selecting an approach to project time and cost planning", International Journal of Project Management, 3 (1): 19-26.

4. CHAPMAN, C.B., COOPER, D.F., DEBELIUS, C.A. and PECORA, A.G. (1985): "Problem solving methodology design on the run", J. Operational Research Society, 36 (9): 769-778. 